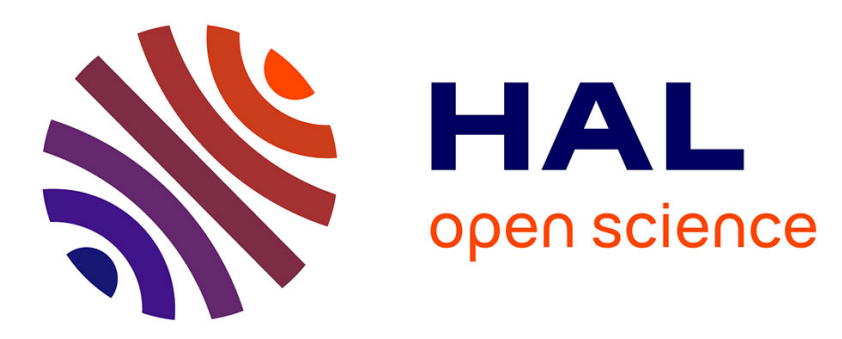

\title{
Recent Advances in Electromagnetic Energy Harvesting and Wireless Power Transfer for IoT and SHM Applications
}

\author{
Alexandru Takacs, Abderrahim Okba, Hervé Aubert, Samuel Charlot, \\ Pierre-François Calmon
}

\section{To cite this version:}

Alexandru Takacs, Abderrahim Okba, Hervé Aubert, Samuel Charlot, Pierre-François Calmon. Recent Advances in Electromagnetic Energy Harvesting and Wireless Power Transfer for IoT and SHM Applications. 2017 IEEE International Workshop of Electronics, Control, Measurement, Signals and their Application to Mechatronics (ECMSM), May 2017, San Sebastien, Spain. pp.299-302, 10.1109/ECMSM.2017.7945868 . hal-01611643

\section{HAL Id: hal-01611643 \\ https://hal.laas.fr/hal-01611643}

Submitted on 6 Oct 2017

HAL is a multi-disciplinary open access archive for the deposit and dissemination of scientific research documents, whether they are published or not. The documents may come from teaching and research institutions in France or abroad, or from public or private research centers.
L'archive ouverte pluridisciplinaire HAL, est destinée au dépôt et à la diffusion de documents scientifiques de niveau recherche, publiés ou non, émanant des établissements d'enseignement et de recherche français ou étrangers, des laboratoires publics ou privés. 


\title{
Recent Advances in Electromagnetic Energy Harvesting and Wireless Power Transfer for IoT and SHM Applications
}

\author{
A. Takacs ${ }^{1}$, A. Okba ${ }^{1}$, H. Aubert ${ }^{1}$, S. Charlot ${ }^{1}$, P-F Calmon ${ }^{1}$ \\ ${ }^{1}$ LAAS-CNRS, Université de Toulouse, CNRS, INSA, UPS, Toulouse, France \\ atakacs@laas.fr, okba@laas.fr, aubert@laas.fr, charlot@laas.fr, calmon@laas.fr
}

\begin{abstract}
This paper addresses the recent advances obtained in LAAS-CNRS Toulouse concerning the development of compact, high-efficiency and multiband RF/microwave energy harvesting devices for autonomous wireless sensors. Several topology of rectenna designed for the Structural Health Monitoring of the satellite antenna panels and for Internet of Things application are discussed.
\end{abstract}

Keywords-energy harvesting, rectennas, space application

\section{INTRODUCTION}

In last decade the demand for Energy Autonomous Wireless Devices (EWAD) experienced an increasing interest. This interest was mainly motivated by the expansion of both traditional and emerging applications including but not limited to Structural Health Monitoring (SHM), Wireless Sensors Networks (WSN) and Internet of Things (IoT). The paradigm of the energetically autonomous wireless devices (sometimes named also batteryless wireless devices) became a reality due to the recent advances in the field of (i) low-power power electronics (concerning the ultra-low power transceivers, sensors and DC boost convertors and regulators), (ii) Energy Harvesting (EH) and (iii) Wireless Power Transfer/transmission techniques (WPT). The energy harvesting supposes that the environmental energy (e.g. solar, mechanical/vibrational, thermal or electromagnetic/RF) is converted locally in DC energy that is used to supply the EWAD. WPT is an alternative solution to EH when the environmental energy lacks and the electrical energy should be provided at distance by the means of electromagnetic waves intentionally generated by a transmitter. By definition, WPT is a technique where electrical energy is transmitted from a power source to a load without the connection of electrical conductors. This paper addresses the recent advances obtained in last years by our team in the field of RF/microwave energy harvesting for space application and in the field of RF EH/WPT for IoT/SHM applications. The key element in any efficient RF EH/WPT systems is the rectenna (an acronym for rectifier antenna). The results obtained in the field of rectenna design for RF/microwave energy harvesting for SHM space application are presented in Section II while the results obtained for IoT applications are described in Section III.

\section{EleCtromagnetic ENERGy HARVESTING FOR SPACE APPLICATION}

The geostationary broadcasting satellites uses high-gain directive RF/microwave antenna in order to establish highreliable data links between the satellite and the Earth. These antenna located on the satellite panels are feed with a high RF power (typically in the range of $100 \mathrm{~W}$ ) in order to overcome the very high propagation losses between the satellite and the Earth. A very promising solution for surveying the health of antenna panels is to use small autonomous Wireless Sensors (WS) composed by one or more sensors connected to a low power transmitter/transceiver. These WS used for thermal or for mechanical/structural monitoring of antenna panel saves the cost and the mass of deploying long wires in harsh environments. In some areas located on antenna panels of broadcasting satellites, the electric field generated by the spillover loss of microwave antennas is significant. The maximum levels (effective value) can reach: $40 \mathrm{~V} / \mathrm{m}$ in C-band, $49.5 \mathrm{~V} / \mathrm{m}$ in X-band, $106 \mathrm{~V} / \mathrm{m}$ in Ku-band and $127 \mathrm{~V} / \mathrm{m}$ in K-band. These high-frequency electromagnetic field levels are available on satellites and almost constant as far as the data links are functional. The concept of electromagnetic energy harvesting in order to power autonomous WS for SHM of the broadcasting satellite antenna panels was first proposed in [1][2] and then developed in [3]. Several rectennas were designed, manufactured and characterized in order to prove the feasibility of such concept. There are presented in the following section.

A. Rectennas: Topologies, Design Methodology and Results

The generic topology of a rectenna is depicted in Fig. 1.

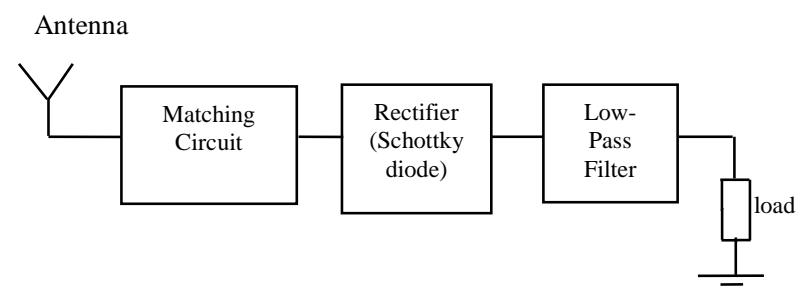

Fig. 1. Generic topology of a rectenna

The key elements of any rectenna are: (i) the antenna that converts the incoming electromagnetic waves in a $\mathrm{RF} / \mathrm{microwave}$ signal and (ii) the rectifier that converts the alternative (RF) signal into DC. A matching circuit/filter must be intercalated between the antenna and the rectifier in order to 
maximize the power transfer between the antenna and the rectifier and to avoid the backscattering (via antenna) of the harmonic frequencies generated by the non-linear elements (e.g. Schotkky diodes, transistors, etc) during rectifying process. The low-pass filter must: (i) maximize the transfer of the DC to the load, (ii) cut-off the RF/microwave frequencies (the main frequency corresponding to the frequency of the incoming waves and its harmonics frequencies generated during the rectifying process) and (iii) optimizing the impact of the input impedance of the load on the rectifier performances. The load represented in Fig. 1 can be: (i) a power management unit (composed by a DC-to-DC convertor/regulator and a storage element - i.e; supercapacitor, rechargeable battery, etc. -) used to regulate the DC power delivered to the input of the WS or (ii) the WS itself. The electromagnetic energy illuminating the satellite antenna panels is almost constant [3] thus for such application the WS can be feed directly by the rectenna. From an application point of view a successful rectenna design can satisfy several criteria concerning mainly: (i) the DC power and voltage delivered to the load, (ii) the efficiency of the RF-to-DC conversion, (iii) the size, (iv) the fabrication cost. Moreover for the targeted application (EH for satellite SHM) the proposed topology should be as simple as possible using components already qualified or pre-qualified for space applications.

In order to prove the feasibility of EH onboard of geostationary satellites several rectenna were fabricated in our laboratory on Rogers 6002 substrate [4] (relative permittivity: 2.94, loss tangent: 0.0012, thickness: $508 \mu \mathrm{m}$, metallization thickness: $35 \mu \mathrm{m})$. There are represented in Fig. 2.
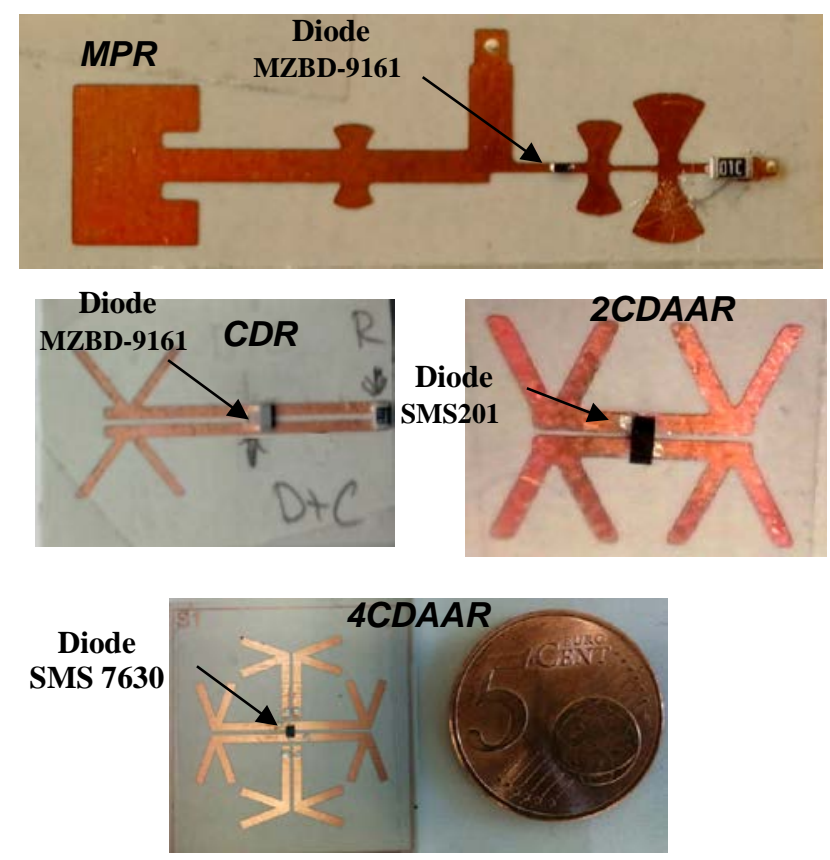

Fig. 2. Rectennas for $\mathrm{EH}$ of the electromagnetic energy onboard of the broadcasting geostationary satellites: MPR (Microstrip Patch Rectenna), CDR (Cross Dipole Rectenna), 2CDAAR : (two Cross
Dipole Antenna Array Rectenna), 4CDAAR (four Cross Dipole Antenna Array Rectenna)

The microstrip patch rectenna (MPR, Fig. 2) is composed by a rectangular patch, a stub based matching circuit and a rectifier using a MA4E-1317 Schotkky diode combined with a distributed low-pass filter (LPF) [3]. The backside is fully (homogenous) metalized. The main drawback of MPR topology is that the rectenna is quite large because of the adopted 'in-line' design. The used antenna is 'narrow band' (the relative frequency bandwidth for a 'classical' rectangular patch is in the range of 5\%). Consequently this topology cannot be accommodated for a broadband/multiband band design. The cross dipole rectenna (CDR, Fig. 2) [5] is composed by a printed cross dipole antenna (CDA) and a rectifier using MZBD-9161 diode [5]. A non-resonant matching technique by properly controlling the mounting position of the Schottky diode and of the DC shunt capacitance was used. The backside of the substrate is not metalized, but a metallic reflector can be positioned bellow CDR in order to increase the rectenna performances. In practice the metallic structure of the satellite antenna panel can be used as reflector. A compact innovative rectenna design was proposed in [6]. This rectenna (2CDAAR, Fig. 2) uses a cross dipole antenna array formed by 2 CDA and a rectifier using a low cost silicon diode (SMS 201) mounted in shunt configuration. The capacitance used for the LPF as well as the resistor emulating the load is mounted on the substrate backside. This design can be optimized in order to obtain a high-efficiency rectenna at a given frequency or a broadband rectenna. A rectenna using a four cross dipole antenna array (4CDAAR, Fig. 2) was proposed in [7]. The rectenna uses a SMS 7630 diode from Skyworks [8] mounted in the center of antenna array. The LPF formed by a $1.5 \mathrm{pF}$ DC capacitor and the resistive load is implemented on the backside of the substrate. 4CDAAR exhibits very good performances at the first resonant frequency (in $\mathrm{Ku}$ band) of the Cross Dipole Antenna Array (CDAA) and also a multiband behavior at frequencies corresponding to the higher resonant modes of the 4CDAA [9].

Reproducing in Laboratory the electromagnetic environment existing on satellite panels is not an easy task. The experimental setup shown in Fig. 3 was used for rectennas characterization.

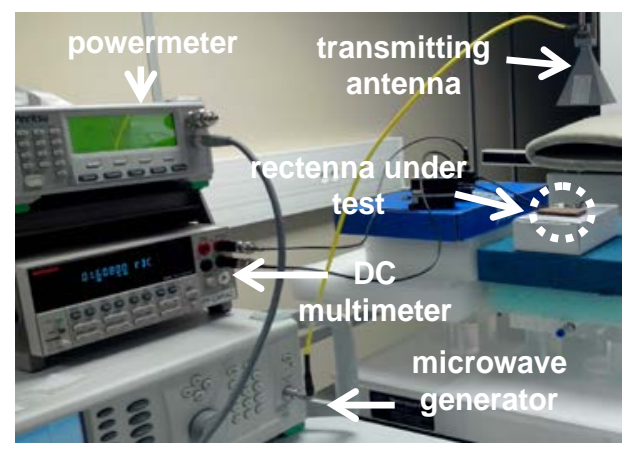

Fig. 3. Experimental setup

A microwave signal provided by an Anritsu MG3694B generator is injected at the input of a transmitting antenna (e.g. 
horn) using a coaxial cable. During the measurement, the rectenna was aligned in order to match the polarization of the transmitting antenna. The transmitting antenna (horn) is placed at a distance $d$ above the rectenna and illuminates the rectenna with a linearly polarized E-field. The harvested DC voltage is measured by using a DC multimeter. The DC power can be derived from the measured DC voltage (the load is known). An automatic acquisition routine is implemented in Labview software from National Instruments to speed-up the acquisition process. From the measured DC voltage/power the efficiency of the rectenna can be computed as follows [10]:

$$
\eta(\%)=\frac{P_{D C}}{S \cdot A_{e f f}} \cdot 100=\frac{4 \cdot \pi \cdot P_{D C}}{S \cdot G_{R} \cdot \lambda^{2}} \cdot 100
$$

where $P_{D C}$ is the harvested DC power, $S$ is the incident electromagnetic power density, $A_{\text {eff }}$ is the antenna effective area, $G_{R}$ is the simulated gain of the (rectenna's) antenna and $\lambda$ is the free-space wavelength of the illuminating electromagnetic wave at a given frequency.

The power density $S\left(\mu \mathrm{W} / \mathrm{cm}^{2}\right)$ can be computed as a function of the E-field effective value $E(\mathrm{~V} / \mathrm{m})$ on the antenna surface or as a function of the RF power $P_{t}$ injected at the input of the transmitting horn antenna (gain $G_{t}$ ) and positioned at a distance $d$ from the rectenna, as follows:

$$
S=\frac{E^{2}}{120 . \pi} \cdot 100=\frac{30 . P_{t} \cdot G_{t}}{d^{2} \cdot 120 . \pi} \cdot 100
$$

The experimental results obtained for 4CDAAR by using the experimental setup represented in Fig. 3 are depicted in Fig. 4. A maximum DC power of $4.5 \mathrm{~mW}$ can be harvested at 12 $\mathrm{GHz}$ when 4CDAAR is illuminated by an E-field of $82.5 \mathrm{~V} / \mathrm{m}$. The highest efficiency of 4CDAAR according to eq. 1 is approximately $40 \%$ for illuminating E-field amplitude ranging between $51 \mathrm{~V} / \mathrm{m}$ and $83 \mathrm{~V} / \mathrm{m}$ [9]. These results confirms that this rectenna can be used for satellite EH/SHM applications. In fact the consumed DC power for a low-power WS is in the range of 1-2 $\mathrm{mW}$ (few $\mu \mathrm{W}$ for the sensors and 1-2 $\mathrm{mW}$ for the state-of-the-art transmitters).

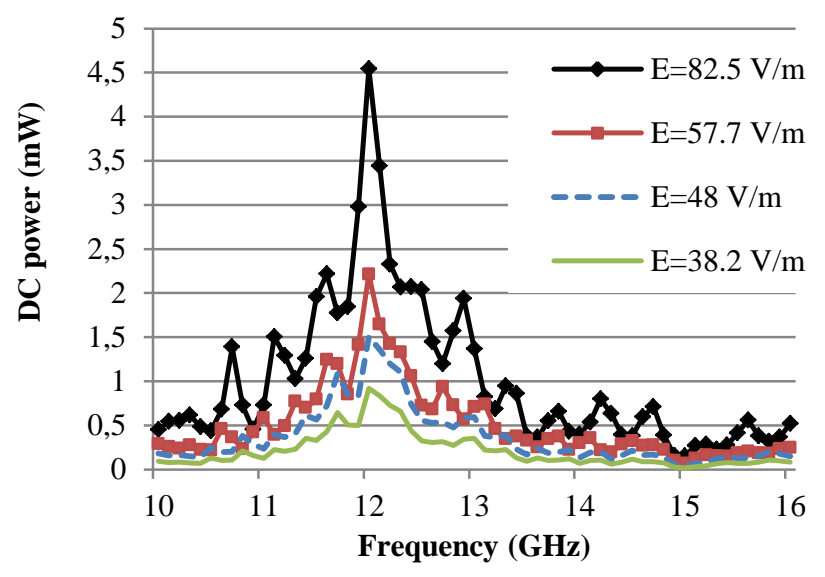

Fig. 4. Experimental results in $\mathrm{Ku}$ band obtained for 4CDAAR representing the harvested DC power at the input port of a resistive load $(\mathrm{RL}=300 \Omega)$ as a function of the frequency for various E-field amplitudes
The proposed rectenna designs (MPR, CDR, 2CDAAR, 4CDAAR) were optimized for various frequencies located in the $\mathrm{Ku}, \mathrm{K}$ and $\mathrm{Ka}$ bands. The key parameters of manufactured rectennas (represented in Fig. 2) are listed in Table I. As shown in this table the proposed rectenna are compact and exhibits a high-efficiency in the range with other design operating at very high frequencies (beyond $15 \mathrm{GHz}$ ).

TABLE I

\begin{tabular}{|c|c|c|c|c|}
\hline $\begin{array}{c}\mathbf{f} \\
(\mathrm{GHz})\end{array}$ & $\begin{array}{c}\eta \\
(\%)\end{array}$ & $\begin{array}{c}\text { Diode } \\
\text { Reference }\end{array}$ & $\begin{array}{c}\text { Size } \\
\left(\mathrm{mm}^{2}\right)\end{array}$ & Reference \& Comment \\
\hline 17.7 & NR & $\begin{array}{l}\text { MA4E- } \\
1317\end{array}$ & 480 & $\begin{array}{l}\text { MPR: harvested DC voltage/power } \\
1.6 \mathrm{~V} / 0.256 \mathrm{~mW} \text { on a load of } 9.1 \mathrm{k} \Omega \\
\text { [3] }\end{array}$ \\
\hline 16.05 & 55 & $\begin{array}{l}\text { MZBD- } \\
9161\end{array}$ & 280 & $\begin{array}{l}\text { CDR: the maximum DC power of } \\
1.4 \mathrm{~mW} \text { is obtained for } \mathrm{RL}=250 \Omega \\
\mathrm{E} \sim 69.28 \mathrm{~V} / \mathrm{m}\left(\mathrm{S} \sim 1.2 \mathrm{~mW} / \mathrm{cm}^{2}\right) \text {, [5] }\end{array}$ \\
\hline 18.8 & 42 & $\begin{array}{l}\text { MZBD- } \\
9161\end{array}$ & 280 & $\begin{array}{l}\text { CDR: E-field of } 91 \mathrm{~V} / \mathrm{m} \quad(\mathrm{S}=2.2 \\
\left.\mathrm{mW} / \mathrm{cm}^{2}\right) \text { for a load of } 510 \Omega,[3]\end{array}$ \\
\hline 14.7 & 48 & SMS201 & 250 & $\begin{array}{l}\text { 2CDAAR: } \quad \mathrm{E}=60 \mathrm{~V} / \mathrm{m} \quad(\mathrm{S}=0.95 \\
\left.\mathrm{mW} / \mathrm{cm}^{2}\right) \text { for a load of } 500 \Omega,[11]\end{array}$ \\
\hline 23.15 & 25 & SMS201 & 250 & $\begin{array}{l}\text { 2CDAAR: } \mathrm{E}=73 \quad \mathrm{~V} / \mathrm{m} \quad(\mathrm{S}=1.4 \\
\left.\mathrm{mW} / \mathrm{cm}^{2}\right) \text { for a load impedance of } \\
300 \Omega,[6]\end{array}$ \\
\hline 12 & 40 & SMS 7630 & 625 & $\begin{array}{l}\text { 4CDAAR: } 51 \mathrm{~V} / \mathrm{m}<\text { E-fields }<82 \\
\mathrm{~V} / \mathrm{m} \text { for a load of } 500 \Omega,[7]\end{array}$ \\
\hline 24 & 24 & $\begin{array}{l}\text { MA4E- } \\
1317\end{array}$ & NR & $\mathrm{S}=10 \mathrm{~mW} / \mathrm{cm}^{2},[12]$ \\
\hline 35 & 35 & $\begin{array}{l}\text { MA4E- } \\
1317 \\
\end{array}$ & NR & $\mathrm{S}=30 \mathrm{~mW} / \mathrm{cm}^{2},[13]$ \\
\hline
\end{tabular}

COMPARISON OF Key PARAMETERS OF THE RECTENNA.

\section{RECTENNA FOR IOT/WPT APPLICATIONS}

The RF EH techniques can be also applied in an IoT scenario. The RF energy is mainly available in the GSM, WiFi and DTV bands but the available levels are weak and time varying. Nevertheless the RF EH techniques, alone or in conjunction with WPT, can be a viable solution for implementing energetically autonomous WSN in an IoT scenario. There is an increasing interest to develop multiband or broadband rectenna in order to exploit any available RF energy source. A rectenna covering the frequency bands around $2.45 \mathrm{GHz}$ : UMTS, ISM $2.45 \mathrm{GHz}$, LTE 4G, WiFi and partially WiMAX (IEEE 802.16e) was recently designed in our laboratory. There is composed by (Fig. 5): (i) a flat dipole antenna located on the top and bottom side of a FR4 substrate (thickness: $0.8 \mathrm{~mm}$, dielectric constant: 4.4 and loss tangent: 0.018) (ii) a rectifier using a Skyworks SMS 7630 diode.

The experimental results for the fabricated antenna are represented in the Fig. 6 and Fig. 7. This antenna exhibits good performances in terms of input matching and radiation pattern: the frequency bandwidth $(\mathrm{S} 11<-8 \mathrm{~dB}$ ) is $800 \mathrm{MHz}$ (from 1.9 to $2.7 \mathrm{GHz}$ ) and the maximum gain is $6.9 \mathrm{dBi}$ at $2.45 \mathrm{GHz}$. 


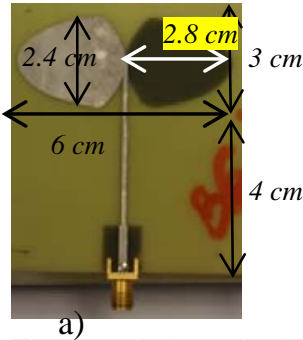

a)

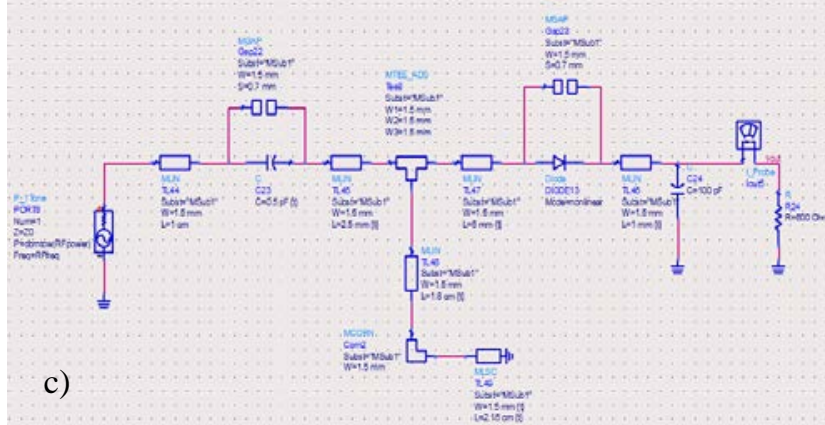

Fig. 5. a) Photo (top side) of the manufactured flat dipole antenna with its main dimensions, b) 3D radiation pattern (gain) simulated with FEKO, c) simulation model (ADS software) of the rectifier.

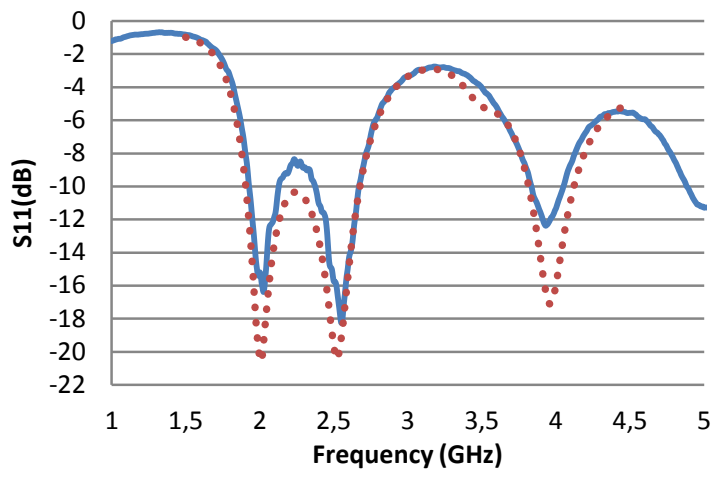

Fig. 6. Measured reflection coefficient (continuous blue line) as function of the frequency for the manufactured flat dipole antenna. The red dotted line represents the simulated reflection coefficient obtained by using FEKO software.

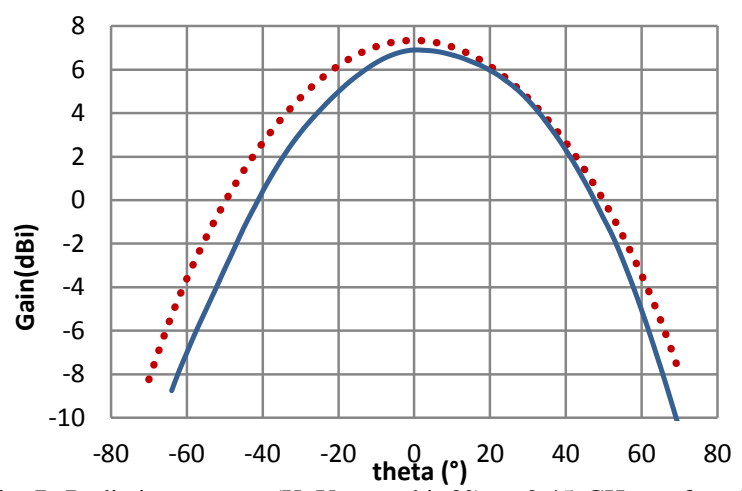

Fig. 7. Radiation pattern (XoY cut, phi $=0^{\circ}$ ) at $2.45 \mathrm{GHz}$ as function of the elevation (theta) angle. Measured (continuous blue line) and the simulated (FEKO, dotted red line) gain are represented as function of theta angle.
The simulation results obtained with ADS software predicts that the rectifier itself exhibits an efficiency of $48 \%$ at $2.45 \mathrm{GHz}$ for an input RF power of $3 \mathrm{dBm}$. The maximum DC power (at the input of a load of $600 \Omega$ ) is $960 \mu \mathrm{W}$ for a $\mathrm{RF}$ power of $3 \mathrm{dBm}$ at the input of the rectifier. The rectifier is under manufacturing and more results concerning the rectifier and the rectenna (obtained by the integration of the flat dipole antenna with the rectifier) will be presented at conference.

\section{CONCLUSIONS}

Several rectenna topologies recently developed at LAASCNRS were presented. The performances of the proposed rectenna designs in the $\mathrm{Ku}, \mathrm{K}$ and $\mathrm{Ka}$ bands prove that the concept of the electromagnetic energy harvesting for the structural health monitoring of antenna panels onboard of the geostationary satellites can became a reality. Nevertheless a lot of research and engineering efforts should be deployed in order to fully qualify the proposed rectenna designs for space applications and to integrate such rectennas with wireless sensors in order to implement energetically autonomous wireless sensors on the satellite antenna panels.

\section{ACKNOWLEDGMENT}

The authors acknowledge the support of French Space Agency within the framework of several past R\&T contracts

\section{REFERENCES}

[1] A. Takacs, H. Aubert, L. Despoisse, S. Fredon, "Microwave energy harvesting for satellite applications," IET Electronics Letters, Issue 11, Vol. 49, pp. 722-723, 23 May 2013.

[2] A. Takacs, H. Aubert, L. Despoisse, S. Fredon, "Broadcast energy", IET Electronics Letters, Issue 11, Vol. 49, 23 May 2013, p. 682.

[3] A. Takacs, H. Aubert, S. Fredon, L. Despoisse, H. Blondeaux, "Microwave power harvesting for satellite health monitoring, IEEE Trans. on Microwave Theory Tech,” Vol.: 62, Issue: 4 , pp. 1090 - 1098, April 2014.

[4] "RT/duroid®6002 high frequency laminates,” Rogers Corporation, Chandler, AZ, USA, 2013. [Online]. Available: http://www.rogerscorp. com/documents/609/acm/RT-duroid-6002-laminate-datasheet.pdf

[5] A. Takacs, H. Aubert, S. Charlot, S. Fredon, L. Despoisse, "Compact Rectenna for Space Application," in Proc. of IEEE IMS'2014, Tampa, USA, 1-6 June, 2014

[6] A. Takacs, H. Aubert, A. Luca, S. Charlot, S. Fredon, L. Despoisse, "Rectenna Design for K Band Application", in Proc. of IEEE European Microwave Conference (EUMC'2014), Rome, Italy, Oct'2014.

[7] A. Okba, S. Charlot, P-F Calmon, A. Takacs, H. Aubert, "Cross dipoles rectenna for microwave applications,” European Microwave Conference, London, UK, 3-7 October 2016.

[8] http://www.skyworksinc.com/Product/511/SMS7630_Series

[9] A. Okba, A. Takacs, H. Aubert, S. Charlot, P-F. Calmon, "Multiband rectenna for microwave applications", Comptes Rendus Physique, Vol. 18, Issue 2, pp 107-117, February 2017

[10] Z. Popovic; E.A. Falkenstein, D. Costinett, R. Zane, Low-Power FarField Wireless Powering for Wireless Sensors, Proceedings of the IEEE, Vol. 101, No. 6, pp.1397 -1407, June 2013.

[11] A. Takacs, H. Aubert, S. Charlot, "Ultra-Compact Ku band Rectenna", in Proc. of IEEE IMS'2015, Phoenix, USA, 17-22 May, 2015

[12] S. Ladan, A. B. Guntupalli, K. Wu, A High-Efficiency $24 \mathrm{GHz}$ Rectenna Development Towards Millimeter-Wave Energy Harvesting and Wireless Power Transmission, IEEE Transactions on Circuits and Systems, Vol. 61, Issue 12, pp. 3358-3366, December 2014.

Y.-J. Ren, M.-Y. Li and K. Chang, $35 \mathrm{GHz}$ rectifying antenna for wireless power transmission, Electronics letters, Vol. 43, Issue 11, pp. 602-603, May 2007. 